\title{
Human Mars Entry, Descent and Landing Architecture Study: Rigid Decelerators
}

\author{
Tara P. Polsgrove ${ }^{1}$, Thomas K. Percy ${ }^{2}$, Jay C. Garcia ${ }^{3}$, \\ NASA Marshall Space Flight Center, Huntsville, AL, 35812, U.S.A. \\ Alicia D. Cianciolo ${ }^{4}$, Jamshid A. Samareh ${ }^{5}$, Rafael A. Lugo ${ }^{6}$, \\ NASA Langley Research Center, Hampton, VA, 23681, U.S.A. \\ Edward A. Robertson, ${ }^{7}$ Chris J. Cerimele ${ }^{8}$, Ron R. Sostaric ${ }^{9}$, \\ NASA Johnson Space Center, Houston, TX, 77058, U.S.A. \\ and \\ Joseph A. Garcia ${ }^{10}$ \\ NASA Ames Research Center, Moffet Field, CA,94035, U.S.A.
}

\begin{abstract}
Several technology investments are required to develop Mars human scale Entry, Descent, and Landing (EDL) systems. Studies play the critical role of identifying the most feasible technical paths and high payoff investments. The goal of NASA's Entry, Descent and Landing Architecture Study is to inform those technology investments. In Phase 1 of the study, a point design for one lifting-body-like rigid decelerator vehicle, was developed. In Phase 2, a capsule concept was also considered to determine how it accommodated the human mission requirements. This paper summarizes the concept of operations for both rigid vehicles to deliver a 20-metric ton ( $t$ ) payload to the surface of Mars. Details of the vehicle designs and flight performance are presented along with a packaging, mass sizing, and a launch vehicle fairing assessment. Finally, recommended technology investments based on the analysis of the rigid vehicles are provided.
\end{abstract}

\section{Introduction}

Several technology investments are required to develop Mars human scale Entry, Descent, and Landing (EDL) systems. In a resource-constrained environment, studies play the critical role of identifying the most feasible technical path sand high payoff investments. One such NASA multi-directorate, multi-center study, is called the Entry, Descent and Landing Architecture Study (EDLAS). EDLAS considered four unique entry technologies to deliver a specified $20 \mathrm{t}$ human scale payload to the Mars surface. This paper focuses on the two rigid decelerator concepts, a capsule evolved from years of previous Mars and Earth entry experience, and an elongated lifting body shape that provides a higher lift-to-drag ratio (L/D) than a typical entry capsule, but lower than a typical winged entry vehicle (such as the Space Shuttle Orbiter). This second option is referred to as the mid-range lift-to-drag ratio or Mid-L/D option. Images of each vehicle are shown in Figure 1.

\footnotetext{
${ }^{1}$ Aerospace Engineer, Exploration System Development Branch.

${ }^{2}$ Aerospace Engineer, Advanced Concepts Office, AIAA Member.

${ }^{3}$ Aerospace Engineer, Advanced Concepts Office.

${ }^{4}$ Aerospace Engineer, Atmospheric Flight and Entry Systems Branch (AFESB), AIAA Senior Member.

${ }^{5}$ Aerospace Engineer, Vehicle Analysis Branch, AIAA Associate Fellow.

${ }^{6}$ Aerospace Engineer, Analytical Mechanics Associates, AFESB, AIAA Member.

${ }^{7}$ Aerospace Engineer, Flight Operations Directorate.

${ }^{8}$ Former Chief, Flight Mechanics and Trajectory Design Branch, AIAA Senior Member.

${ }^{9}$ Aerospace Engineer, Flight Mechanics and Trajectory Design Branch, AIAA Senior Member.

${ }^{10}$ Aerospace Engineer, Systems Analysis Office, Aeronautics Directorate, AIAA Senior Member.
} 


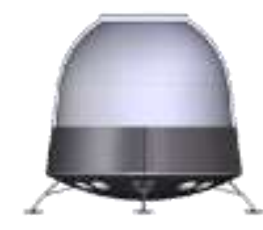

(a) Capsule

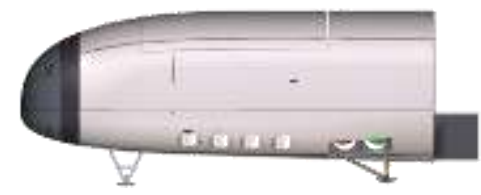

(b) Mid L/D

Figure 1. Images of the EDLAS Rigid Decelerator concepts.

NASA's Human Exploration and Operations Mission Directorate (HEOMD) provides the reference Mars architecture, Mars surface lander payload manifests, and ground rules and assumptions used in this study. Each decelerator must integrate with four lander payload configurations. While rigid decelerator options provide superior payload protection from entry environments and orbital debris, they constrain payload packaging geometry and deployment options once on the Martian surface. A full description of the EDLAS ground rules and assumptions, as well as an overview of the Human Mars architecture used for this study, are presented in Ref 1.

Beyond the primary objective of providing technology recommendations, EDLAS sought to identify EDL vehicle concepts of operations and ensure that they were compatible with HEOMD defined architecture elements in other mission phases. An additional objective uses flight performance simulations to identify technology developments in areas of guidance and control, engine performance and navigation to meet the landing constraints.

The next section describes the concept operations for the rigid vehicles to deliver 20t payload to the surface of Mars. In contrast to robotic missions that jettison ballast mass, separate a backshell and heatshield and deploy parachutes prior to landing, the human scale concept of operations includes no jettison events because multiple landers are delivered to the same surface location. Eliminating jettison events reduces risk of impacting critical pre-deployed surface assets. Additionally, human scale missions will not use parachutes as a primary drag device. Parachutes do not scale well, even in clusters, for the large entry vehicles. The large mass increase requires a parachute drag area that is not achievable in a single chute or even clusters. Likewise, large vehicle diameter increases the parachute trailing distance to 100 's of meters making chutes infeasible. Therefore, engines are used to slow the vehicles for descent and landing and must initiate while the vehicle is still traveling at supersonic speeds. The use of supersonic retropropulsion (SRP) changes the entry guidance and the trajectory profile in a way that is drastically different from robotic missions and requires additional modifications to the flight system. A summary of the analysis performed to evaluate the vehicle design and payload integration is also provided in Section II. Likewise, Section III presents the flight performance analysis and results.

Section IV presents additional studies performed using the rigid vehicles. The first considers the scalability of the Mid L/D to smaller precursor class missions. A second explores the feasibility of using the rigid vehicles as the SLS launch fairing. One unique aspect of both of the rigid decelerator options is the potential for the decelerator to serve a dual function and protect the payloads during launch from Earth, eliminating the need for a payload fairing. This approach impacts lander and launch vehicle designs, and could eliminate the need for a 10-meter Space Launch System (SLS) payload fairing, a fairing option that may only be used for the Mars lander flights. The aerodynamic loads during launch affect launch vehicle structural design, and the launch environments including acoustics and aerodynamic loading affect the lander design. The impacts to the vehicle design due to scaling and using the vehicle as the launch vehicle fairing are described in Section V.

Ultimately, the objective of the study is to provide the NASA Space Technology Mission Directorate (STMD) with technology investment recommendations. Section VI provides the study findings and recommendations with respect to rigid decelerators.

\section{Concept of Operations}

A key objective of the architecture study is to ensure that the vehicle design is compatible with all phases of the mission. EDLAS considers Earth launch through surface operations at Mars. Past studies have considered Earth prelaunch facility accommodations [2] so they are not included here. Likewise, a description of the Mars architecture used for this study is provided in Ref [1] and is not repeated here. It is noted that four (three cargo and one crew) landers are required to support a 300-day mission. While the payload configurations are different, the EDL sequence is identical for each lander using a specific entry technology. This consistent sequence enables the cargo landers to serve as end-to-end flight demonstrations for the fourth crew entry vehicle. The following subsections describe the vehicle design and configurations in each phase of flight for the Mid L/D and Low L/D capsule vehicle configurations. 


\section{A. Mid L/D}

A detailed description of the Mid L/D vehicle is provided in [3]. The specific vehicle shape is derived from the Co-Optimization Blunt-body Re-entry Analysis (COBRA) shape optimization process at the NASA Ames Research Center and the parametric Cobra shape class. Therefore, the vehicle is referred to as the Cobra Mid L/D Rigid Vehicle (CobraMRV). EDLAS Phase 2 sought to increase the fidelity of the mass estimate for the CobraMRV vehicle to support comparisons with the other decelerator concepts by defining materials, loads, optimization constraints and margins. The analysis also considers the mass trade of including cargo bay doors and performing a packaging assessment. An image of the reference CobraMRV vehicle design with dimensions is provided in Figure 2. The vehicle is designed to fit within the $10 \mathrm{~m}$ SLS launch fairing which has a dynamic envelope (inner usable diameter) of $9.1 \mathrm{~m}$.

The updated CobraMRV mass is based on finite element model (FEM) created using Pro Engineer Computer Aided Drawing (CAD) and MacNeal-Schwendler Corporation (MSC) Patran software. MSC Nastran was used as a linear solver (SOL 101) and Collier Research Hypersizer was used for structural sizing optimization.

The finite element model is shown in Figure 3. The rocket motors, fuel tanks and Mars Ascent Vehicle (MAV) are assumed to be rigid and modeled using high stiffness properties. Multi-Point Constraints are used to attach these components to the vehicle. The mass of these rigid components is included in the model by using element volume along with calculated mass density as required.

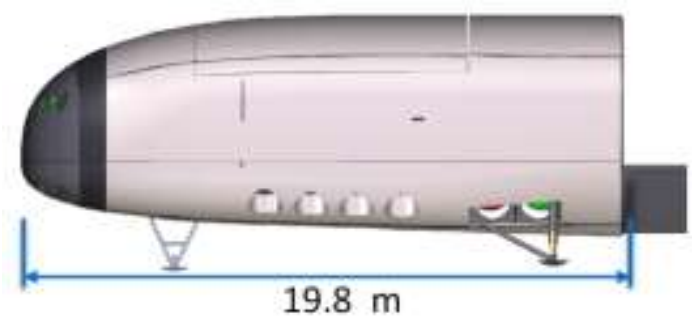

(a) Side view

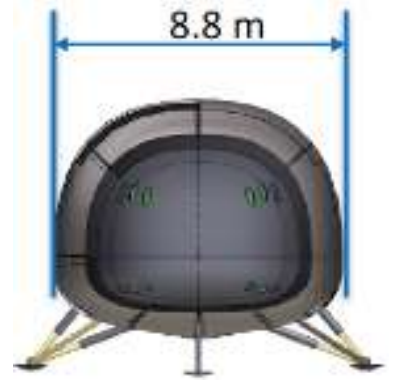

(b) Front view

Figure 2. CobraMRV vehicle configuration with dimensions.
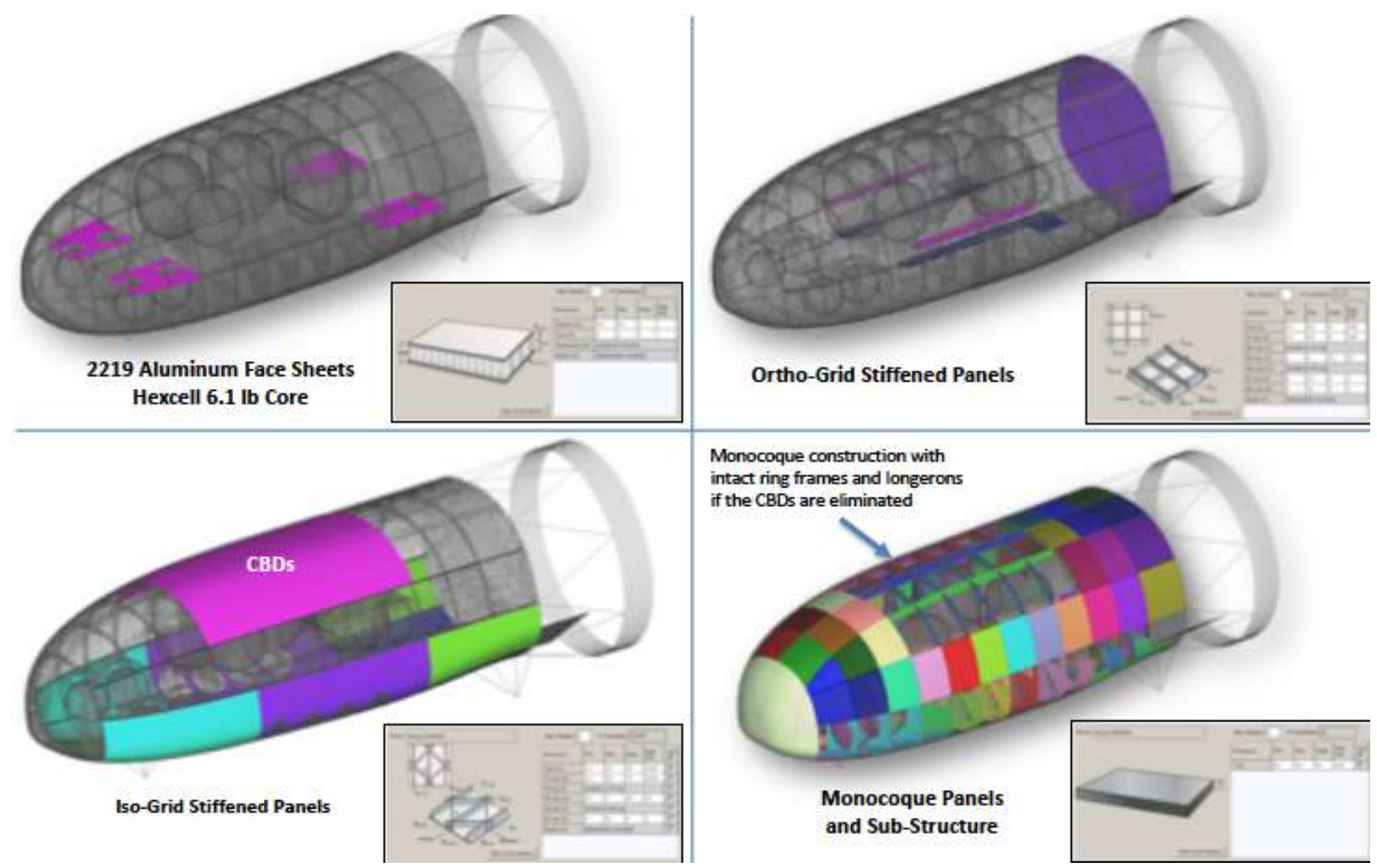

Figure 3. CobraMRV Finite Element Grids

Two CobraMRV configurations were analyzed, one with and one without Cargo Bay doors. Structural sizing of the CobraMRV vehicle assumes Aluminum 2219 construction. A total of four load cases were applied to the 
CobraMRV model to represent earth launch / ascent and Mars entry loading events. Load cases evaluated are defined as follows: Load Case 1 - Earth launch/ascent assumes +5 Earth g Axial and +/-2 Earth g Lateral accelerations; Load Case 2 - Mars aero entry uses mapped pressure fields at peak dynamic pressure; Load Case 3 - Mars Propulsive descent (All motors firing at full thrust simultaneously); Load Case 4 - Mars landing assuming a maximum of 3 Earth g's.

The CobraMRV configuration with Cargo Bay Doors uses stiff CBUSH elements to simulate latch locations around the perimeter of each door. The lower skin panels are covered in SIRCA-15 ablator and are deflection limited subject to a radius of curvature constraint of less than 400 inches similar to the Orion design approach. The overall TPS design is shown in [3].

The mass estimate for the CobraMRV with and without the cargo bay doors (CBD's) is shown in Table 1. A few key differences are noted. The primary and secondary structure masses differ as a result of the finite element analysis shown above. The mass of Category 5 - Thermal mass was increased by $250 \mathrm{~kg}$ for the case without cargo bay doors to account for the articulated panels that protect the in-space radiators during aerocapture and entry and uncover them for active cooling during orbital and transit phases. Additionally, Category 6.3 - Mechanisms in the configuration without cargo bay doors was increased by approximately $600 \mathrm{~kg}$ to address the requirement for aft deployment of the MAV for launch, as opposed to a vertical launch through a CBD opening. In all, the differences in gross mass between the two configurations was less than $100 \mathrm{~kg}$. Subsystem masses for power, avionics and propulsion are identical across the two vehicle configurations. Propellant mass is based on change in velocity estimates obtained from flight performance results described in the next section and RCS allocations presented in [1]. This provided the basis for the EDLAS Phase 2 CobraMRV design update.

Table 1. Mid L/D Master equipment list for design with and without cargo bay doors.

\begin{tabular}{|c|c|c|c|c|c|c|c|}
\hline & \multicolumn{3}{|c|}{ Without cargo bay door } & \multicolumn{3}{|c|}{ With CBD } \\
\hline ID & System & $\begin{array}{c}\text { Basic } \\
(\mathrm{kg})\end{array}$ & $\begin{array}{l}\text { MGA } \\
(\%)\end{array}$ & $\begin{array}{c}\text { Predicted } \\
\text { (kg) }\end{array}$ & $\begin{array}{c}\text { Basic } \\
(\mathrm{kg})\end{array}$ & $\begin{array}{l}\text { MGA } \\
(\%)\end{array}$ & $\begin{array}{l}\text { Predicted } \\
\text { (kg) }\end{array}$ \\
\hline 1.0 & Structure & 12318 & $20.0 \%$ & 14782 & 12970 & $20.0 \%$ & 15564 \\
\hline 1.1 & Primary Structure & 10698.4 & $20 \%$ & 12838.1 & 11482.4 & $20 \%$ & 13778.9 \\
\hline 1.2 & Secondary Structure & 1619.7 & $20 \%$ & 1943.6 & 1487.7 & $20 \%$ & 1785.2 \\
\hline 2.0 & Propulsion & 4241 & $24.1 \%$ & 5263 & 4241 & $24.1 \%$ & 5263 \\
\hline 3.0 & Power & 953 & $27.7 \%$ & 1217 & 953 & $27.7 \%$ & 1217 \\
\hline 4.0 & Avionics & 269 & $23.7 \%$ & 333 & 269 & $23.7 \%$ & 333 \\
\hline 5.0 & Thermal & 675 & $25.0 \%$ & 844 & 475 & $25.0 \%$ & 594 \\
\hline 6.0 & CobraMRV & 4487 & $22.5 \%$ & 5499 & 4027 & $22.5 \%$ & 4901 \\
\hline 6.1 & Thermal Protection System (TPS) & 2526.8 & $20.0 \%$ & 3032.2 & 2526.8 & $20.0 \%$ & 3032.2 \\
\hline 6.2 & Aerosurfaces & 400.0 & $30.0 \%$ & 520.0 & 400.0 & $30.0 \%$ & 520.0 \\
\hline 6.3 & Mechanisms & 740.0 & $30.0 \%$ & 962.0 & 280.0 & $30.0 \%$ & 364.0 \\
\hline 6.4 & Landing Gear & 820.5 & $20.0 \%$ & 984.6 & 820.5 & $20.0 \%$ & 984.6 \\
\hline DRY & & 22943 & $21.8 \%$ & 27937 & 22935 & $21.5 \%$ & 27871 \\
\hline 7.0 & Cargo & 20000 & $0.0 \%$ & 20000 & 20000 & $0.0 \%$ & 20000 \\
\hline 8.0 & Non-Propellant & 911 & $6.0 \%$ & 966 & 911 & $6.0 \%$ & 966 \\
\hline INERT & & 43854 & & 48902 & 43846 & & 48837 \\
\hline 9.0 & Usable Propellant & 15018 & & 15018 & 14998 & & 14998 \\
\hline 9.1 & Usable Propellant (MPS) & 9886.2 & & 9886.2 & 9873.0 & & 9873.0 \\
\hline 9.2 & Usable Propellant (RCS) & 4905.3 & & 4905.3 & 4898.7 & & 4898.7 \\
\hline 9.3 & Engine Start/Stop Transient (MPS) & 226.6 & & 226.6 & 226.6 & & 226.6 \\
\hline GROSS & & 58872 & & 63921 & 58845 & & 63835 \\
\hline
\end{tabular}

Figure 4 shows the EDLAS Phase 2 updated CobraMRV in each phase of flight. In the Launch configuration, the vehicle is rotated 90 degrees and stacked vertically to fit within the $10 \mathrm{~m}$ diameter SLS launch fairing. The SLS delivers the CobraMRV to a high Earth orbit where it docks with the in-space solar electric propulsion (SEP) transportation stage. The Transit configuration in Figure 4 shows that there is adequate distance between the solar arrays of the in-space transportation stage for the CobraMRV to dock with the transfer vehicle. Cargo missions perform aerocapture into a one Sol orbit at Mars. Therefore, two days prior to Mars arrival, the lander vehicle separates from the transportation stage and reorients using Reaction Control System (RCS) thrusters for aerocapture. The current 
atmospheric phase control method, described in the next section, uses body flaps and RCS for control and are notionally shown in the Figure 4 Mars Arrival configuration.

During transit, the lander obtains power from the transportation stage. After separation and aerocapture, the lander must maintain power in orbit for up to one year. Therefore, the Mars Orbit configuration shows solar arrays deployed. Likewise, radiators are needed for thermal management. The concept shown includes both radiators and solar arrays deployed on the aft end of the body. Another concept includes radiators on the cargo bay doors. In the latter (not shown), the doors would remain open during the Mars orbit loiter.

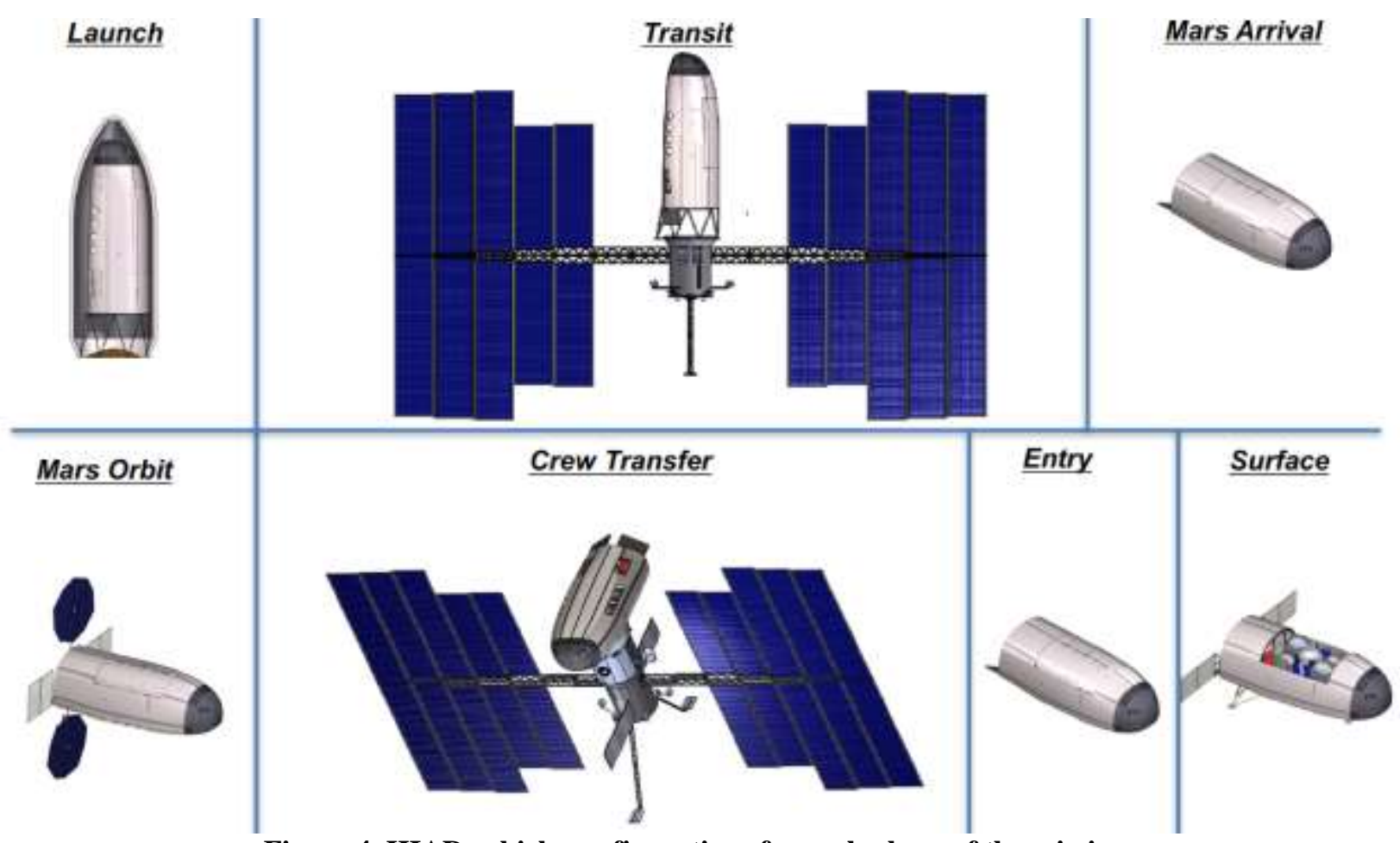

Figure 4. HIAD vehicle configurations for each phase of the mission.

For the lander that will deliver crew to the surface, it must dock with the crew transfer vehicle when it arrives. The Crew Transfer image in Figure 4 shows that there is adequate clearance from the transit stage. The orbiting arrays and radiators on the vehicle are stowed or jettison prior to docking. In the current configuration, the crew habitat is located in the central portion of the vehicle. Therefore, the CobraMRV docks in a configuration that is perpendicular to the SEP stage solar arrays. An alternative option is to include a tunnel to the habitat inside the CobraMRV that extends to aft doors, in which case, the docking configuration may look similar to the Transit configuration. The docking configuration will be refined as the CobraMRV design matures.

Three cargo landers are delivered to Mars and perform aerocapture and final checkout in orbit prior to initiating deorbit for EDL. After full checkout and proper phasing is achieved, the cargo landers jettison the orbit arrays and stow radiators, perform the deorbit burn and reorient for entry using RCS thrusters. Since the same control approach is used for aerocapture and entry, the vehicle configurations are identical, shown in

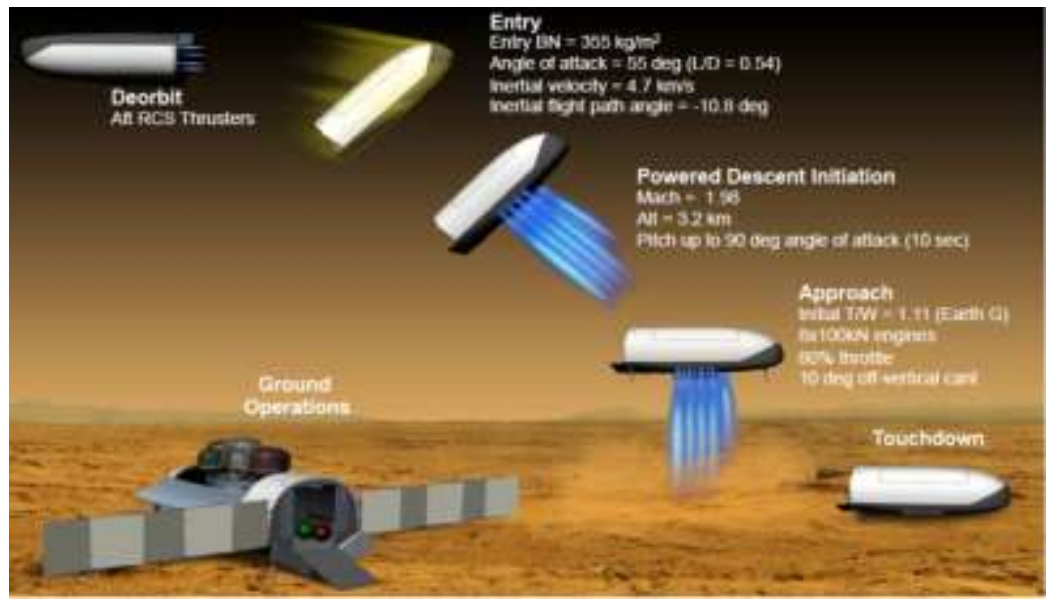

Figure 5. MID L/D vehicle EDL concept of operations. 
the Entry image of Figure 4. One key difference from earlier human scale EDL studies [4,5] is that no elements are jettisoned during EDL because all the vehicles are delivered to the same landing zone within $50 \mathrm{~m}$ of a designated target. Vehicles can land no closer than $1 \mathrm{~km}$ from any previously landed assets to reduce the risk of impact from the regolith displaced by the descent engines. Many events occur during EDL, therefore Figure 5 shows details of the sequence for the Mid L/D vehicle. The vehicle enters with an angle of attack near $55 \mathrm{deg}$. At approximately Mach 2, the vehicle attitude is changed to 90 degrees angle of attack and initiates engines for descent and touchdown. Once on the surface, radiators are deployed to support thermal management of the cryogenic storage facility on the MAV lander. The landers are equipped with batteries that are sized to support operations on the surface for 24 hours to allow time to connect to the previously landed surface power supply. The image is shown in the Surface configuration image in Figure 4. A rear door is also deployed (not shown) to act as a ramp for accessing cargo during surface operations. In addition, for the CBD version, cargo can be accessed via cranes through the open cargo bay doors.

Packaging assessments of the Mid L/D lander option showed that all four payload manifests could be accommodated with one modification. The reference surface habitat design is oriented as a vertical cylinder. This element was too tall to fit in the Mid L/D lander. However, the same pressurized volume can be accommodated in a horizontal orientation, so it appears to be feasible to deliver a comparable surface habitat using the CobraMRV. The reconfigured habitat configuration is shown in Figure 6d. Habitability assessments, including layout of the internal design of a horizontally oriented habitat, have not been assessed to verify acceptability of this solution.

This section has summarized the vehicle updates, mission phase concept of operations and payload packaging for the CobraMRV. The next subsection will review similar aspects for the second rigid concept, the capsule.

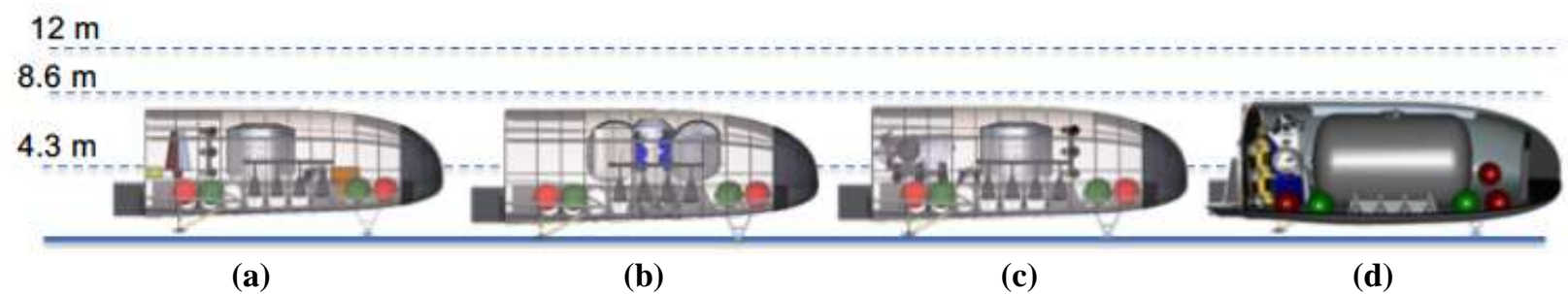

Figure 6. Four lander packaging arrangements for the Mid L/D vehicle.

\section{B. Capsule}

The capsule shape has been used for human entry at Earth beginning with the Soviet Union's Vostok and NASA's Gemini, Mercury and Apollo programs, as well as the current Orion project. The shape was adapted for Mars entry capsules for Viking and all Mars missions thereafter. Therefore, EDLAS Phase 2 added the capsule concept to the vehicle configuration evaluations to determine the feasibility of the design to accommodate the HEOMD defined payload configurations [1]. Figure 7 shows several shapes shape options, including the Apollo [6], Apollo D-2 [7], and Soyuz backshell shapes considered for the study.

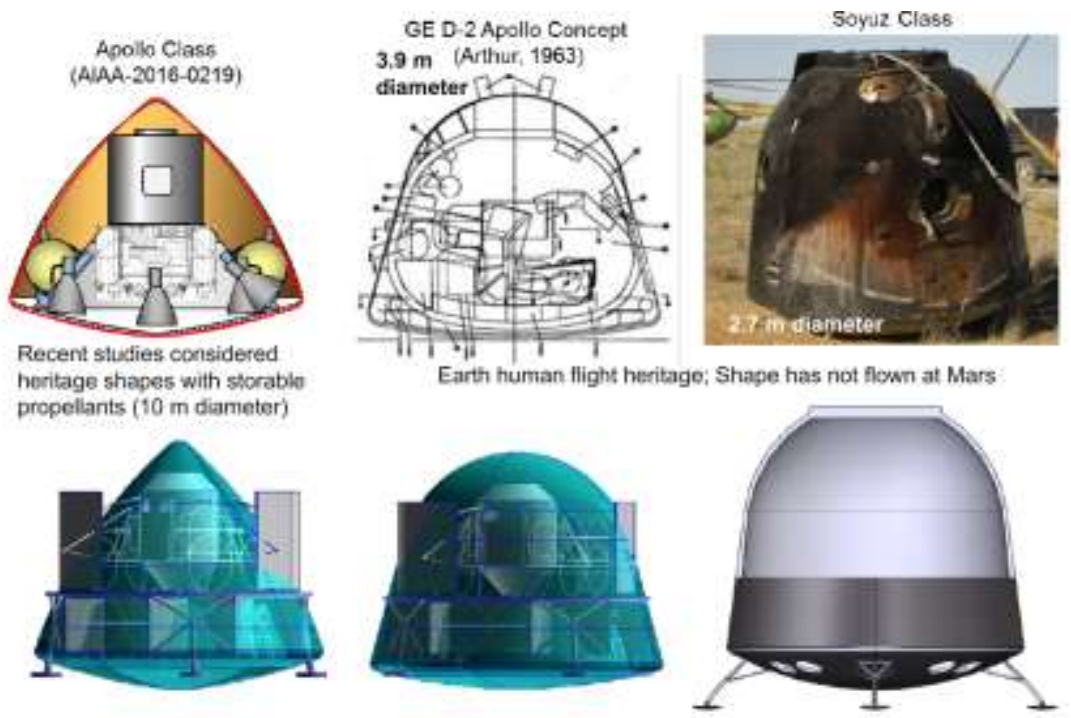

Figure 7. Outer mold lines considered for the capsule configuration. 
The Soyuz shape was selected to maximize payload volume. The key design drivers were the $10 \mathrm{~m}$ SLS fairing diameter limit. Due to the already volume constrained vehicle, the capsule configuration is the only lander that also serves as the launch fairing and is not subjected to the $9.1 \mathrm{~m}$ dynamic envelope limit. The final capsule shape was a version of the Soyuz scaled from the $2.7 \mathrm{~m}$ diameter Russian flight vehicle to $10 \mathrm{~m}$ diameter for the human Mars configuration.

The single largest indivisible payload element is the Mars Ascent Vehicle (MAV). Ground rules state that, to minimize risk, it cannot be assembled on the surface of Mars, and so, must be delivered as a single unit. Various backshell configurations were considered to accommodate the reference MAV design. Likewise, several MAV configurations were considered. Despite the packaging efforts, the $10 \mathrm{~m}$ diameter capsule configuration was unable to accommodate the reference MAV. Therefore, to minimize changes to the overall architecture, a smaller, less capable MAV, scaled from the reference design, is assumed here. Since the reduced propellant capacity MAV can only deliver to a low Mars orbit (lower energy than the 1-sol reference orbit), an additional taxi element is added to the capsule concept of operations. The taxi element is delivered to Mars orbit as an additional element by an existing transport or as an additional transport system. Regardless of how it is delivered to Mars, it adds an additional launch to the architecture and extends the overall mission. It adds risk as an additional required element compared to the other entry vehicle configurations considered. The use of a taxi is not included in the reference architecture defined in Ref 1.

The EDLAS capsule concept uses a common lander configuration that is similar to the one used for deployable decelerator concepts described in Ref 8 . Therefore, it assumes a $10 \mathrm{~m}$ rigid heatshield design with doors to expose eight engines and four landing gear. Since the lander is encapsulated, radiators on the lander are redesigned to be deployed on orbit with the solar arrays. Figure 8 shows the dimensions of the capsule vehicle.

The capsule design includes finite element structural analysis of all primary structure, thermal protection system design, as well as landing system structures and propulsion design. Structural components are designed to withstand decelerations of three Earth g's. The vehicle dimensions define the area for the heatshield, backshell, frustum, and stiffeners. The backshell is assumed to be stiffened skin made of Aluminum 2024 covered by room temperature vulcanizing (RTV) insulation and Super Lightweight Ablator (SLA-5610) $0.64 \mathrm{~cm}$ thick. The heatshield material is an aluminum honeycomb stiffened skin or sandwich with a carbon fiber-reinforced polymer (CFRP) composite laminate system face-sheet called IM7 and a layer of RTV with Phenolic-Impregnated Carbon Ablator (PICA) ablative TPS $(1.86 \mathrm{~cm})$. The design for the heatshield and TPS are shown in Figure 9. Frustum, shown in green in Fig. 9, is made of Al-2024 skin and ten stiffeners. Twelve parameters; including skin thickness, height and width of rings and stiffeners; were used to minimize the total mass.

A hot structure design was the alternative TPS concept, which consists of ACC-6, OFI, and a thin layer of Nextel. This concept is similar to that used in [9] for an alternative entry concept. The fidelity of hot structure design is not adequate at this time to warrant additional discussion. The total aeroshell mass for the capsule with margin was nearly seven metric tons. The master equipment list for the capsule structure is shown in Table 2.
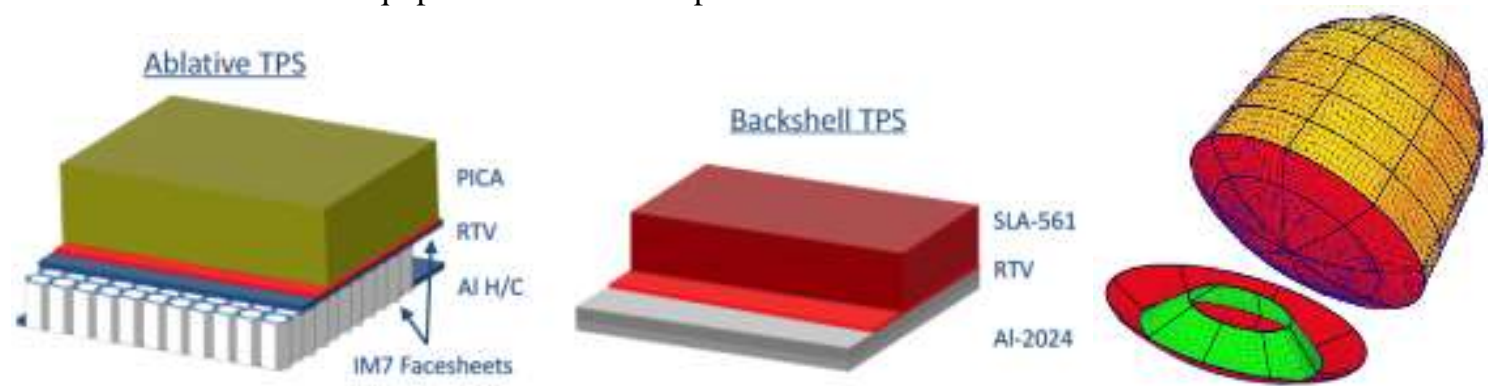

Figure 9. Material layup and finite element model grid for the capsule configuration. 
Table 2. Capsule structural mass estimate.

\begin{tabular}{|c|c|c|c|c|c|c|c|}
\hline \multirow{2}{*}{ Subsystem } & Component & Quantity & $\begin{array}{c}\text { Unit Mass } \\
(\mathrm{kg})\end{array}$ & CBE (kg) & MGA \% & MGA (kg) & MEV (kg) \\
\hline \multirow{3}{*}{ Aeroshell } & Heatshield Structure + TPS & $\mathbf{1}$ & $\mathbf{1 , 8 9 3}$ & $\mathbf{1 , 8 9 3}$ & $\mathbf{3 5 \%}$ & $\mathbf{6 6 3}$ & $\mathbf{2 , 5 5 6}$ \\
\cline { 2 - 8 } & Backshell Structure + TPS & $\mathbf{1}$ & $\mathbf{3 , 3 1 0}$ & $\mathbf{3 , 3 1 0}$ & $\mathbf{3 5 \%}$ & $\mathbf{1 , 1 5 8}$ & $\mathbf{4 , 4 6 9}$ \\
\cline { 2 - 8 } & TOTAL & & & & & & $\mathbf{7 , 0 2 5}$ \\
\hline
\end{tabular}

Figure 10 shows the EDLAS Phase 2 capsule configuration in each phase of flight. While the Launch configuration shows the capsule in the SLS $10 \mathrm{~m}$ fairing, the notional design is to fly without the added fairing mass. The SLS delivers the capsule to a high Earth orbit where it will dock with the in-space solar electric propulsion (SEP) transportation stage notionally using the same launch vehicle attach points in the heatshield. The Transit configuration in Figure 10 shows that there is adequate distance between the solar arrays of the in-space transportation stage for the capsule. Similar to all configurations, the lander obtains power from the transportation stage during transit. Two days prior to Mars arrival, the cargo missions separate from the transfer stage, reorient using RCS thrusters, and performs aerocapture into a one Sol orbit at Mars. The entry configuration is shown in Figure 10 Mars Arrival. The current entry control method considers flaps (not shown in Figure 10) that are described in the following section. After separation and aerocapture, the lander must produce its own power in orbit for up to one year. Therefore, the Mars Orbit configuration shows solar arrays deployed. Radiators are also required for thermal management in orbit and will be deployed similar to the solar arrays but are not shown in the image.

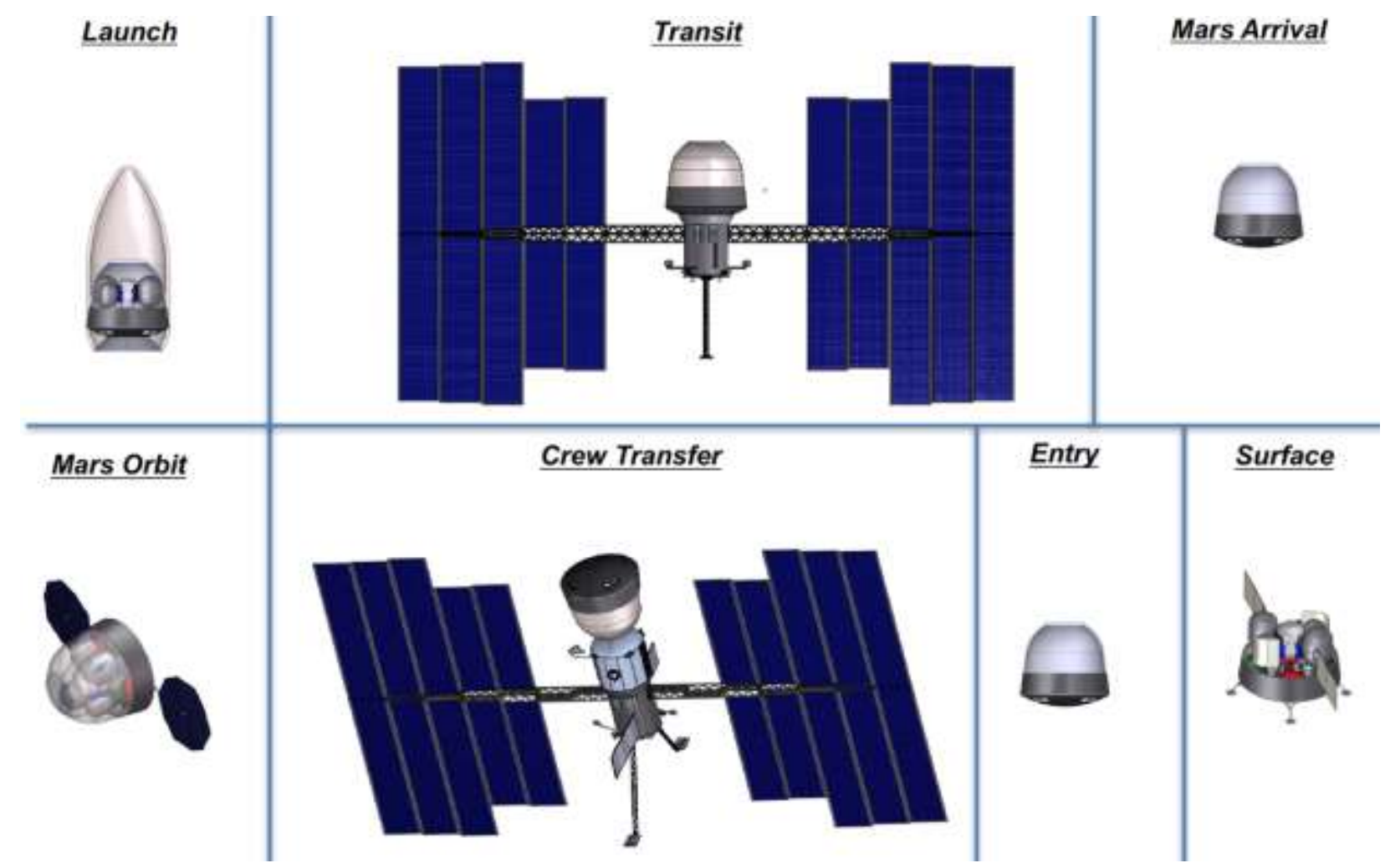

Figure 10. Capsule vehicle configurations for each phase of the mission.

The lander that will deliver crew to the surface must remain in orbit and dock with the crew transfer vehicle when it arrives. The Crew Transfer image in Figure 10 shows that there is adequate clearance between the capsule and the transit stage. The orbiting arrays are stowed or jettison prior to docking. The crew capsule must dock with the crew transfer vehicle, shown in Figure 10 Crew Transfer, in a configuration that is opposite from the capsule configuration in the Transit configuration for the crew to access the habitat. 


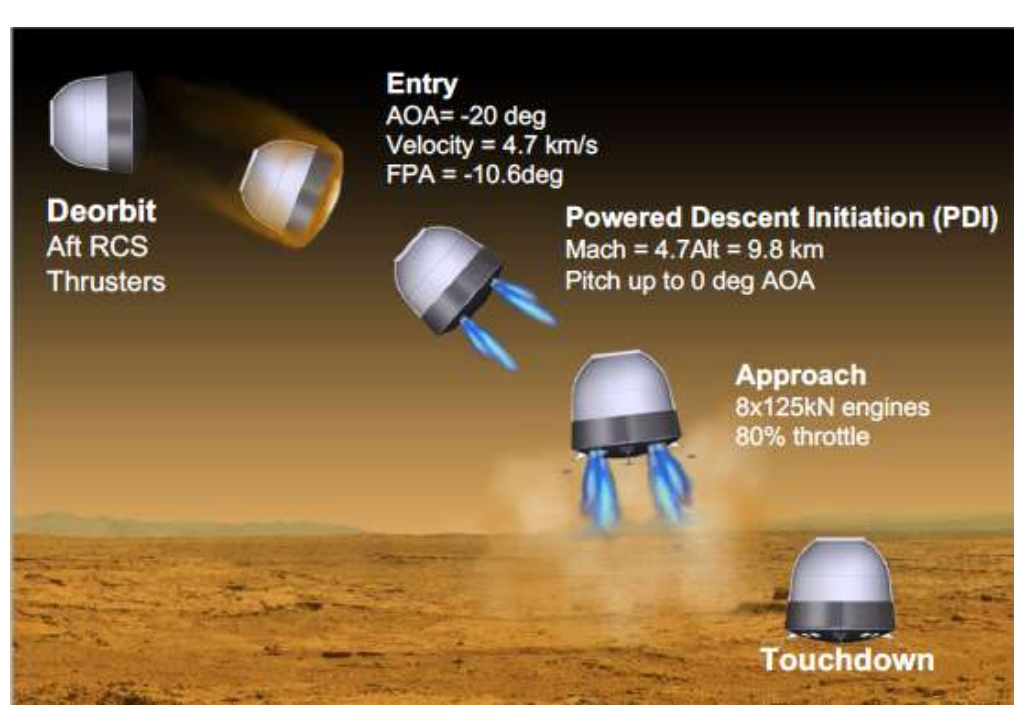

Figure 11. HIAD vehicle EDL concept of operations.

The Entry configuration in Figure 10 is identical to the Mars Arrival aerocapture configuration. Once EDL is initiated with a deorbit burn using RCS thrusters, the vehicle reorients for entry and flies with an angle of attack of near negative 20 deg. At approximately Mach 4.7, the engines are initiated and the vehicle angle of attack is reduced to 0 deg. The engines slow the vehicle for landing. Details of the EDL sequence are shown in Figure 11. Once on the surface, the backshell separates into sections and is jettisoned. This allows access to and deployment of other payloads such as surface power systems and rovers. Additionally, it provides unrestricted operation of the Mars Ascent Vehicle which will carry the crew back to orbit at the conclusion of the surface mission. The backshell pieces will create a debris area around the lander, complicating payload offloading, but it may be possible to move one or more sections of the backshell once they have been separated. The surface payload manifest for human missions includes a crane for moving payloads, which may be able to reposition portions of the backshell, or rovers may be able to move pieces away. Removal of the backshell will impact the timeline of the surface operations. Currently the lander batteries are sized to provide 24 hours of power and time to connect to the previously landed power station. Analysis has not been performed to determine if removal of the backshell is compatible with the surface operations timeline. Likewise, once on the surface, additional radiators will be deployed to support generation and storage of the MAV cryogenic propellants. The capsule Surface configuration is shown in Figure 10.

While care was taken to maximize available payload volume, the capsule option remained the most constrained of the four options considered in the EDLAS study. In addition to the challenges of packaging the MAV, other interference issues persisted with two other payload manifests considered. Lander 3, which contains the pressurized rover, logistics module, and surface mobility elements could not all fit into the capsule volume resulting in the need for an additional capsule. Likewise, the monolithic (all-in-one) habitat volume defined for the 300-day mission could not be accommodated in the $10 \mathrm{~m}$ high backshell. Therefore, the capsule configuration considered a modular habitat and divided it into two. Doing so complicates surface operations as the hardware associated with moving landers must be included and the habitat designs have to be modified. Maintaining the same payload delivery requirements as the other configuration, to support a crew of 4 on the surface for 300 days, was a challenge for the volume constrained capsule configuration. Figure 12 shows the images of the capsules required to deliver the HEOMD defined payloads.

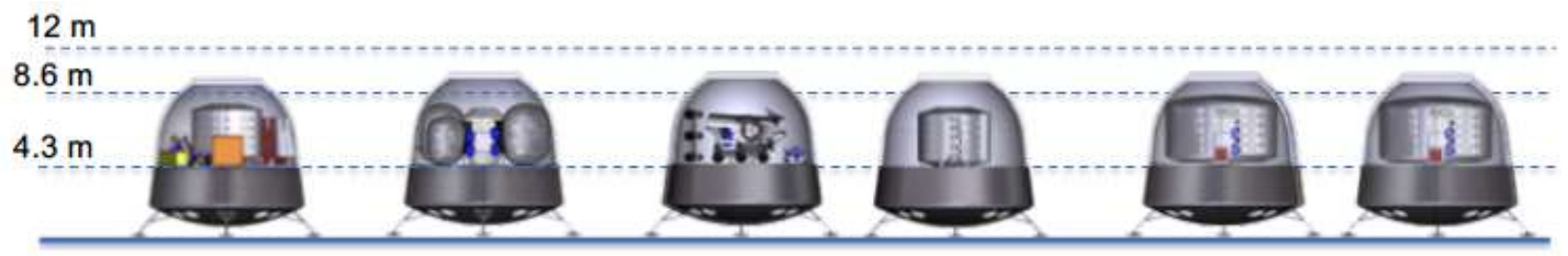

Figure 12. Capsule packaging configurations.

Not only did the concept need a smaller MAV, which necessitated an extra architecture element (and extra launch), two additional landers are needed to accommodate payload volume restrictions. In total, the capsule concept required three extra launches and two extra landers to deliver the same payload manifest as the other vehicles considered in EDLAS. SLS has a limited launch cadence of to two launches per year, therefore, the three extra launches extend the launch schedule by an additional year and a half. Additionally, now six landers have to be delivered to a specific landing zone which translates into larger landing zones and more dispersed payloads. The current architecture repeats this sequence three times to complete the full mission manifest. Therefore, the additional cost with respect to number of launches, extended schedule and number of landers makes this configuration least favorable of the concepts being 
considered. Having to meet the constraint of fitting with in the SLS $10 \mathrm{~m}$ fairing would reduce the capsule diameter to $9.1 \mathrm{~m}$ and impact the packaging further. Under the circumstance that only the $8.4 \mathrm{~m}$ fairing was imposed, with a $7.5 \mathrm{~m}$ usable fairing diameter, it is likely that even more landers would be required to deliver all the payload elements.

\section{Master Equipment List}

The master equipment list for the rigid vehicles is provided in Table 3. It is noted that the power, avionics and payload elements are identical between the vehicles. The propulsion mass depends on the total amount of propellant used; more propellant translates to larger tanks and associated structures. The final CobraMRV MEL was updated slightly from the cargo bay door comparison shown in Table 1 . The structures element for the capsule comprises the common lander stage and is consistent across the designs that use the common vertical lander configuration. Efforts to use common subsystem assumptions resulted in a slight increase in CobraMRV power mass and the non-propelled fluids, which include coolants for thermal control. Also, updating the RCS allocations to be consistent across the designs resulted in an increase in total propellant used for both vehilces. Therefore, the study results indicate that rigid vehicles used to deliver $20 \mathrm{t}$ payloads to Mars have launch masses greater than $65 \mathrm{t}$ with the assumptions and design details used in this study.

Table 3. Rigid vehicle master equipment list summary.

\begin{tabular}{|c|c|c|}
\hline \begin{tabular}{l|l} 
ID & Subsystem
\end{tabular} & Capsule & CobraMRV \\
\hline \begin{tabular}{l|l}
1.0 & Structures
\end{tabular} & 5,422 & 14,836 \\
\hline \begin{tabular}{l|l}
2.0 & Propulsion \\
\end{tabular} & 5,215 & 5,190 \\
\hline \begin{tabular}{l|l|}
3.0 & Power \\
\end{tabular} & 1,568 & 1,568 \\
\hline \begin{tabular}{l|l|}
4.0 & Avionics \\
\end{tabular} & 333 & 333 \\
\hline 5.0 Thermal & 218 & 844 \\
\hline \begin{tabular}{l|l}
6.0 & Aero decelerator \\
\end{tabular} & 7,025 & 5,499 \\
\hline Dry Mass & 19,781 & 28,270 \\
\hline \begin{tabular}{l|l}
7.0 & Cargo \\
\end{tabular} & 20,000 & 20,000 \\
\hline \begin{tabular}{l|l}
8.0 & Non-Propelled Fluids \\
\end{tabular} & 1,965 & 1,523 \\
\hline Inert Mass & 41,746 & 49,793 \\
\hline \begin{tabular}{l|l}
9.0 & Used Propellant \\
\end{tabular} & 26,531 & 16,399 \\
\hline Total Stage Gross Launch Mass & 68,277 & 66,192 \\
\hline
\end{tabular}

\section{Vehicle Performance}

This section presents the assumptions, analysis, and results of the CobraMRV and Capsule flight performance using different entry and descent guidance schemes. The resulting propellant loads are used to size the propellant tanks and associated hardware in the MEL. The Program to Optimize Simulated Trajectories (POST2) is the trajectory simulation used to characterize performance for the guidance comparison. The simulations are initiated at deorbit of a polar one Sol orbit $(250 \mathrm{~km} \times 33800 \mathrm{~km})$, therefore the entry velocity is $4.8 \mathrm{~km} / \mathrm{s}$. The entry time corresponds to a minimum in the Mars pressure cycle (May 10, 2033) and the landing target is near the equator. Three degree-offreedom Monte Carlo analysis is performed for each configuration using vehicle specific aerodynamics models with uncertainties and the Mars Global Reference Atmosphere Model (Mars-GRAM 2010) [10] with dispersions. The simulations assume perfect navigational knowledge and no dispersion of the entry state.

The study compares two different entry guidance approaches. The entry approaches include heritage bank angle control (denoted BNK) and direct force control (DFC). Bank angle control guidance has been used since the Gemini missions and at Mars with the Science Laboratory mission. It uses mass to offset the center of gravity and uses RCS thrusters to change the bank angle in order to steer the vehicle to a desired location. However, it has not been used to meet landing targeting constraints of $50 \mathrm{~m}$ (other than the Space Shuttle Orbiter). The second entry guidance considered has not been flown at Mars but functions much like body flaps on an aircraft. The concept assumes some mechanism (flaps, movable mass, shape deformation, etc.) can be modulated during flight such that aerodynamic forces (i.e. of angle of attack and sideslip) can be controlled independently. No such mechanisms have flown on a Mars mission but wind tunnel testing has been performed to characterize the impact of adding a flap to a rigid blunt body shape [11]. For this study, the trajectory simulation models the effect of such a system without assuming an implementation. 
The study also considers two different variations in gravity turn powered descent guidance approaches. In the first, a pure gravity turn (PGT), in which the thrust is aligned with the velocity vector, the descent guidance determines the pitch and yaw rates required to hold a zero-degree angle of attack and side slip ( 90 degree angle of attack in the case of the CobraMRV). The second approach is called an augmented gravity turn (AGT). In this approach, the guidance algorithm determines the pitch and yaw rates to hold the desired angle of attack and sideslip angle that minimize landing errors. The primary difference in the approaches is that the latter allows for small variations in the vehicle angle of attack and sideslip during descent and the former forces them to be along the relative velocity vector. In both approaches, predicted landing errors are fed back into the entry guidance to null out targeting dispersions before the powered descent phase initiates. During the powered descent phase, thrust magnitude is adjusted to acquire the desired touchdown velocity at the desired altitude. The study assumes that all thrust variations are performed using differential throttling, not gimbaled engines. Eight $100 \mathrm{kN}$ engines throttled at $80 \%$ is the nominal thrust level $(640 \mathrm{kN})$ to accommodate dispersions.

8001 Monte Carlo cases were run for the different scenarios. Parameters included in the Monte Carlo analysis are shown in Table 4. Key metrics include ability to meet the $50 \mathrm{~m}$ to target at $0 \mathrm{~km}$ above the Mars Orbiter Laser Altimeter areoid landing criteria, propellent used, landed altitude and angle of attack at engine initiation. The following subsections presents the simulations and results for CobraMRV and Capsule analysis.

Table 4. Monte Carlo parameters

\begin{tabular}{|l|l|}
\hline \multicolumn{1}{|c|}{ Parameter } & \multicolumn{1}{c|}{ Dispersion /Distribution } \\
\hline Center of Gravity Location & $\pm 0.05 \mathrm{~m} \mathrm{3 \sigma}$ \\
\hline Mass & $\pm 500 \mathrm{~kg} 3 \sigma$ \\
\hline Aerodynamics Coefficients & MSL Aerodynamic Uncertainties \\
\hline Atmosphere & $\begin{array}{l}\text { Dust tau: 0.1-0.9 uniform } \\
\text { Mars-GRAM 2010 density dispersions }\end{array}$ \\
\hline
\end{tabular}

\section{A. Mid L/D}

CobraMRV entry control used in this study is derived from shuttle experience, while the entry guidance uses a numerical predictor-corrector constant bank approach. It uses body flaps and RCS to control bank angle and angle of attack during entry according to guidance commands. Studies of descent flight performance show that the CobraMRV vehicle, with an $\mathrm{L} / \mathrm{D}$ of 0.55 , can achieve the required landing accuracy with alpha modulation and sufficient thrust. Figure 13 shows the landing site dispersion for two cases. The left side shows the effect of using bank angle guidance with alpha modulation (BCAM) and a pure gravity turn with $640 \mathrm{kN}$ thrust. While most cases do meet the landing requirement (97\% have a miss distance less than $55 \mathrm{~m}$, see Figure 14), many do not. The cases that missed also failed to meet the $0 \mathrm{~km}$ altitude criteria shown in Figure 15.

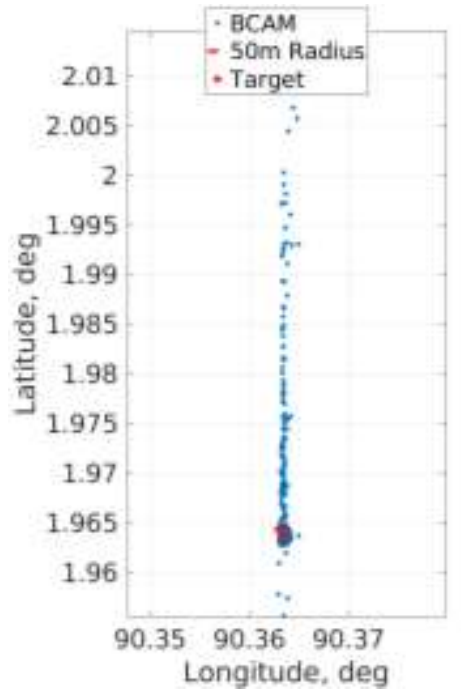

(a)

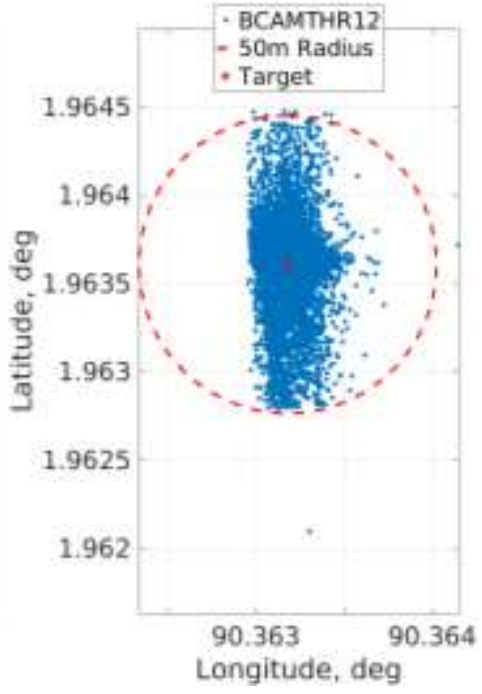

(b)

Figure 13. CobraMRV Monte Carlo landing foot print results.

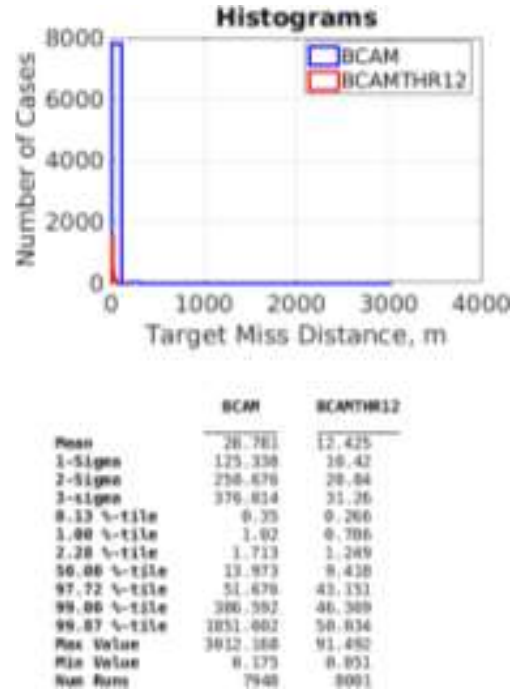

Figure 14. Target miss distance. 

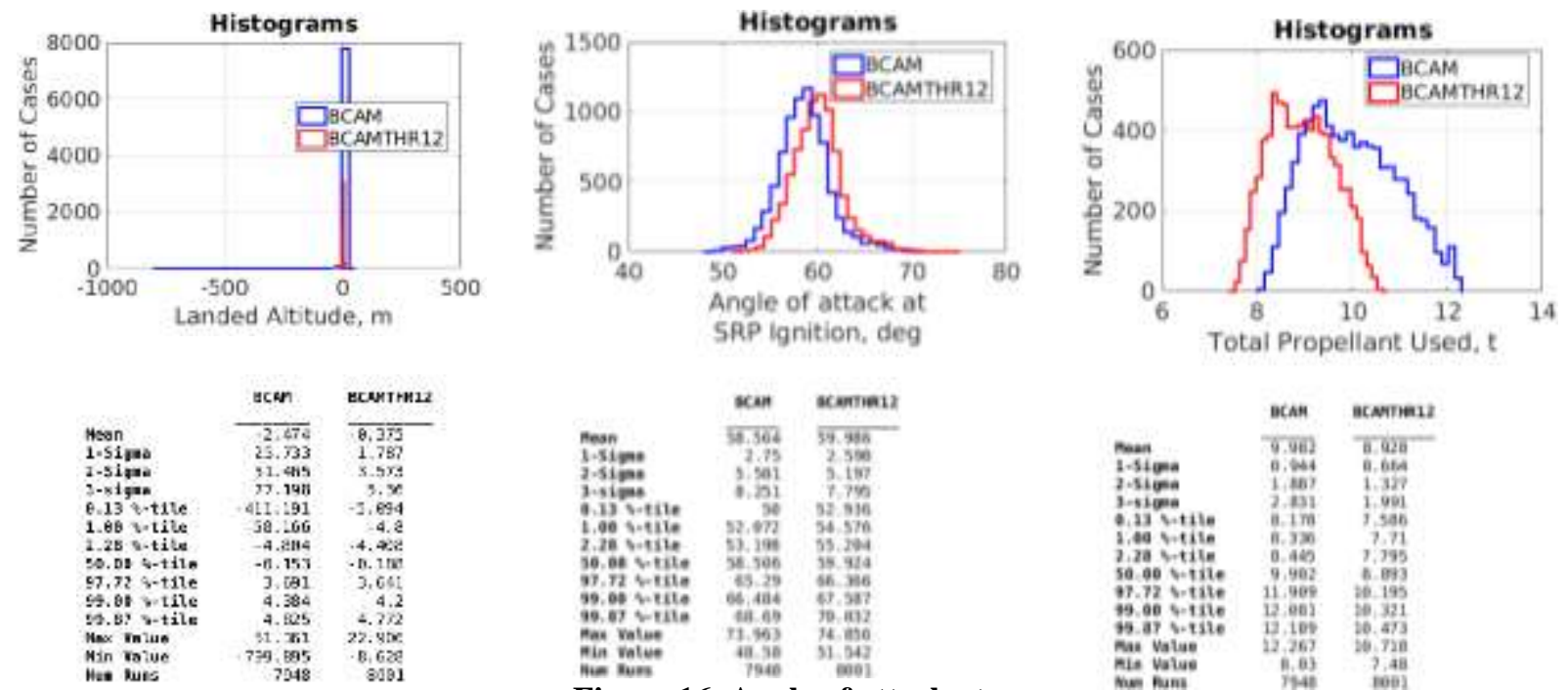

Figure 15. Miss distance.
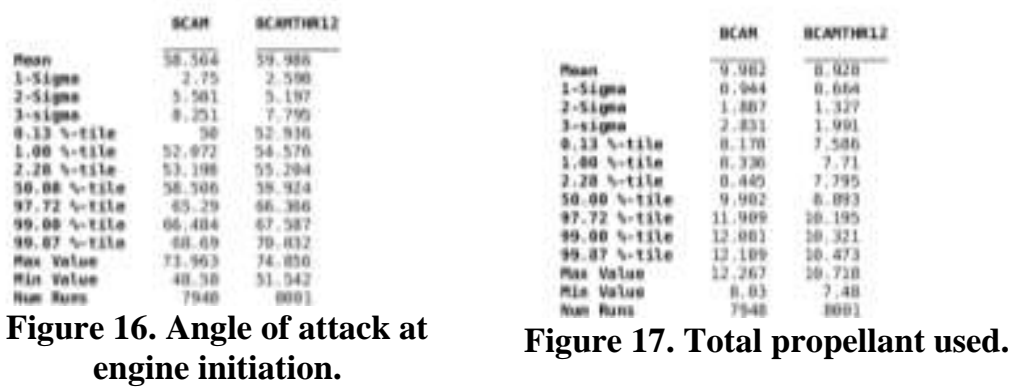

Figure 17. Total propellant used.

Therefore, instead of switching to AGT (which was not analyzed for mid-L/D in this study), the thrust was simply increased by $20 \%$ (almost 2 engines) and the case was reevaluated. Figure 13b (BCAMTHR12) shows that the added thrust was sufficient to bring $99.87 \%$ of the cases within the required red landing circle. In addition, more recent analysis has shown that very successful targeting can be accomplished with $640 \mathrm{kN}$ thrust when closed-loop (position) powered descent guidances are used.

Additionally, Figure 16 shows the angle of attack at engine initiation between 50 and $70 \mathrm{deg}$. This is a concern for transitioning to the powered descent phase that will be addressed in future studies. Likewise, Figure 17 shows the total propellant use for the two cases. The higher thrust level effectively reduces the mean and distribution of propellant use. While this targeting analysis was performed using 3DOF simulations, much work has been done throughout the study to refine the $6 \mathrm{DOF}$ entry controller. That work is summarized in Ref $[12,13]$.

\section{B. Capsule}

Historical low lift-to-drag (L/D) vehicles with similar blunt forebody shapes have flown guided entries using bank angle control with an a L/D near 0.24 or greater, and an angle of attack during entry near 15 deg or larger. For the large human scale capsule lander using bank angle control and gravity turn powered descent, studies have shown that additional $\mathrm{L} / \mathrm{D}$, up to 0.3 , is needed to meet the landing constraints at Mars. However, unlike robotic Mars missions that jettison approximately $2.5 \%$ of the entry mass as ballast prior to entry to achieve the desired L/D and then again prior to parachute deploy to rebalance the vehicle, this is not a practical approach to changing L/D for the human vehicles, especially with the elimination of jettison events and parachutes. A mass efficient approach to achieve the L/D offset and enable direct control of aerodynamic forces during aerocapture and EDL is to use actuated trim tabs or other methods (flaps, movable mass, etc.). While these methods enable the capsule to meet the landing accuracy requirements for the mission, the vehicles limited drag area results in a ballistic coefficient near $500 \mathrm{~kg} / \mathrm{m}^{3}$ (compared to $380 \mathrm{~kg} / \mathrm{m}^{3}$ for the Mid L/D option and $155 \mathrm{~kg} / \mathrm{m}^{3}$ for the two deployable decelerator options). Therefore, the vehicle initiates the engines near Mach 5 and relies more on propulsive deceleration during descent requiring more than twice the propellant load of the other options studied.

Three different entry and descent guidance combinations were simulated for the capsule. The first assumed the heritage bank angle entry guidance and a pure gravity turn descent guidance. This case used an L/D $=0.3$ and assumed the L/D was achieved using a deployable flap. RCS thrusters were used to achieve the bank commands and reversals. Bank angle rates, based on the Apollo experience, are limited to a maximum of $15 \mathrm{deg} / \mathrm{s}$ and bank angle accelerations are limited to $5 \mathrm{deg} / \mathrm{s}^{2}$. Initial results indicated that the $800 \mathrm{kN}$ at $80 \%$ throttle setting was not sufficient to meet the landing constraints with a gravity turn powered guidance. In fact, nearly doubling the number of engines was still not sufficient to meet the landing constraint. Figure 18 shows the landing point results for the case where the total thrust is increased by a factor of 1.875 (15 engines at 100\%). The label BNKPGT1875 represents bank angle guidance, pure 
gravity turn, thrust factor 1.875. Therefore, landing performance was analyzed using DFC (using angle of attack and sideslilp control rather than bank angle control), achieved assuming four flaps are orientated 90 deg around the capsule on the outer edges of the heatshield. By commanding the flaps to achieve aerodynamic forces on angle of attack and sideslip independently, the errors at engine initiation were reduced. In the absence of DFC experience for blunt body vehicles, angle rates and accelerations were selected with flight performance constraints and controller development in mind. Therefore, the maximum angle of attack rate and accelerations are set to $5 \mathrm{deg} / \mathrm{s}$ and $2 \mathrm{deg} / \mathrm{s}^{2}$ respectively and the maximum side slip angle rate and accelerations are $0.3 \mathrm{deg} / \mathrm{s}$ and $2 \mathrm{deg} / \mathrm{s}^{2}$ respectively. Additionally, the descent guidance used the augmented gravity turn (AGT) for more accurate descent control. However, the 8001 cases still did not meet the landing requirements using the nominal engine setting of $800 \mathrm{kN}$. Therefore, two additional throttle settings were added: the first with a thrust factor of 1.5 and another with a thrust factor of 1.2. The landed foot print results are shown in Figure 18b (DFCAGT15) and 18c (DFCAGT12). It is noted that just changing from a pure gravity turn to an augmented gravity turn was not sufficient to reduce the landing footprint error.

The analysis assumes a $10 \mathrm{~m}$ diameter capsule has an entry mass of $63 \mathrm{t}$ and a ballistic coefficient is $500 \mathrm{~kg} / \mathrm{m}^{2}$. Other key metrics include target miss distance shown in Figure 19 and angle of attack at engine initiation shown in Figure 20. This plot shows how DFC reduces the angle of attack at engine initiation. Likewise, increasing the total engine thrust reduces propellant used, as shown in Figure 21. However, the study indicates that the high ballistic coefficient capsule concept will need approximately twice the propellant to deliver the same 20t payload compared to the other concepts.

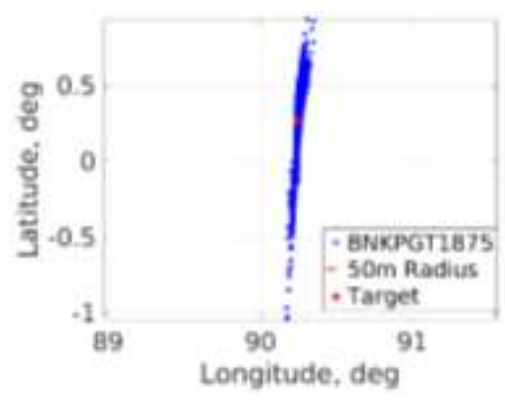

(a)

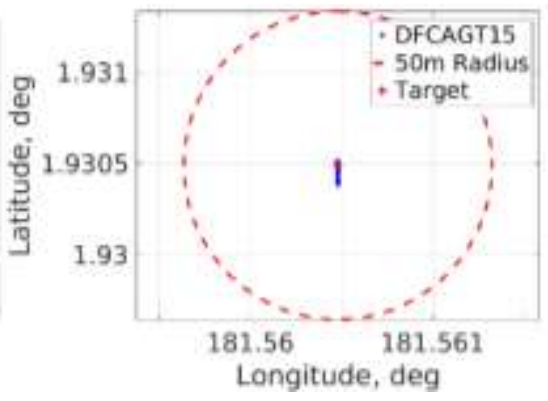

(b)

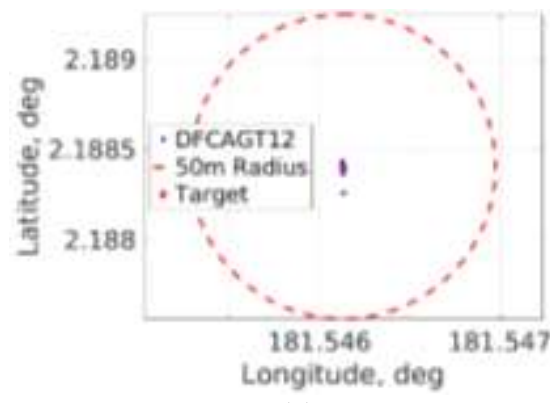

(c)

Figure 18. Monte Carlo landing foot print results.
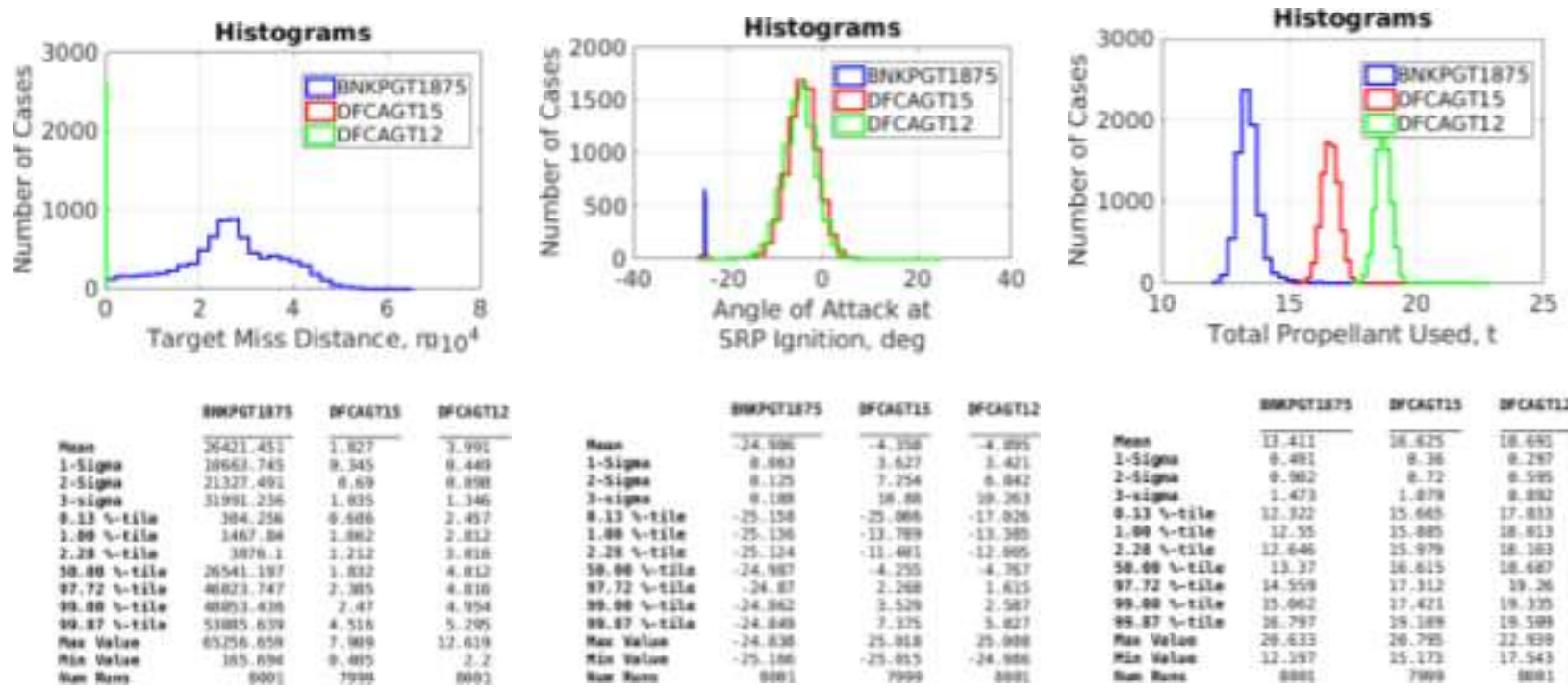

Figure 19. Miss distance.

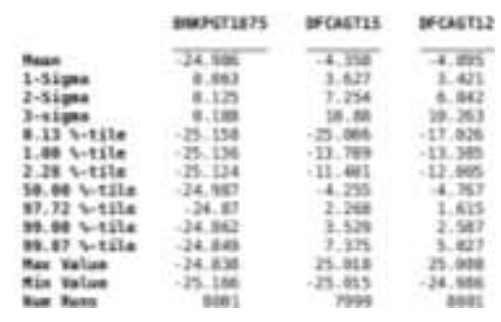

Figure 20. Angle of attack at engine Initiation.

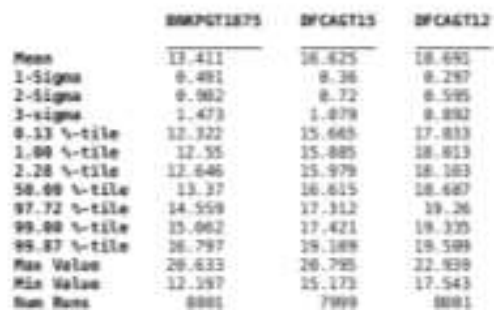

Figure 21. Total propellant used. 


\section{Additional Studies}

\section{A. Precursor Design}

An end-to-end (deorbit to landing) test of a human scale EDL vehicle concept prior to full scale flight is not strictly required to validate systems needed for the crewed missions, as EDL validation can be performed via a piecemeal strategy. If an opportunity to fly a precursor mission does become available, however, the ability to test a smaller version than full-scale is desired. In capsule case, scaling the state of the art up to a $5 \mathrm{t}$ payload class has been studied previously, and has been shown to be feasible. However, a Mid L/D vehicle has not flown at Mars. Therefore, EDLAS explored the use of
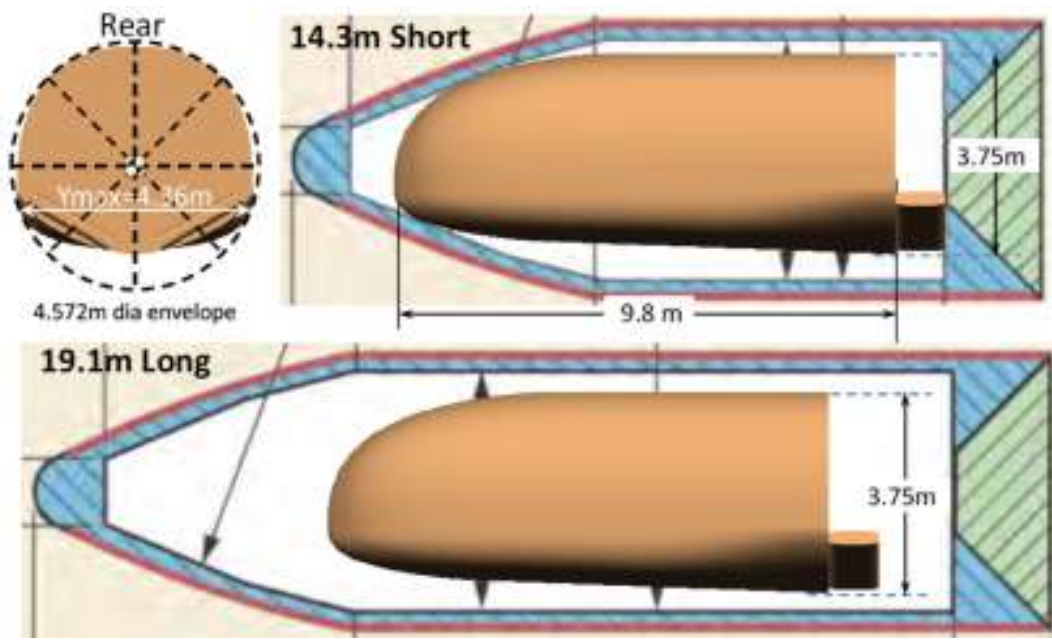

Figure 22. Mid L/D EDLAS vehicle photographically scaled by $49 \%$ to fit in the Delta IV Heavy long and short fairing. photographic scaling of the Cobra MRV to fit in the nose shroud of a current launch vehicle. As an example, the Delta IV Heavy long and short payload fairing. An image of the scaling is shown in Figure 22. The study considered the amount of usable volume, center of gravity location restrictions and potential payloads. A sample precursor mission considered both Science Mission Directorate (SMD) payloads and HEOMD precursor mission class payloads. For example, a precursor mission might carry a SMD sample return-like payload with a fetch rover and a small Mars assent vehicle (with an approximate mass and volume of $1.5 \mathrm{t}$ and $12.6 \mathrm{~m}^{3}$ ). Likewise, an accompanying payload could be the quarter- to half-scale human precursor kilowatt power payload and/or similarly scaled in situ resource utilization (ISRU) plant [14], with mass and power estimates of $2.5 \mathrm{t}$ and $30 \mathrm{~m}^{3}$. Initial analysis showed that a CobraMRV, photographically scaled to $49 \%$-scale, fits within the Delta IV long envelope and a slightly smaller scale (or with a stowed body flap) can be accommodated by the Delta IV short envelope and have payload volume to accommodate both the SMD and HEOMD precursor payload. To maintain the same ballistic coefficient of the full-scale mission, the vehicle could accommodate a payload mass of up to 10t. However, the design has limitations on volume, the lateral dimension of the cargo bay doors may be a factor for offloading cargo or a rear offloading ramp could be demonstrated. A subscale CobraMRV configured for aft cargo extraction seems best suited to support precursor missions involving a mixture of fixed and mobile cargo elements.

\section{B. Launching without a Fairing}

The Mid-L/D vehicle was designed to fit within a 10m SLS payload fairing (PLF) with a maximum dynamic envelope (inner usable diameter) of $9.1 \mathrm{~m}$. The SLS Block 1B launch fairing diameter is currently $8.4 \mathrm{~m}$ with a dynamic envelope of $7.5 \mathrm{~m}$. If a suitable $10 \mathrm{~m}$ SLS PLF is not developed for the SLS Block II configuration, then the alternatives would be to either fly the Mid-L/D Mars lander without a PLF or scale down the Mid-L/D vehicle to fit within an existing SLS PLF envelope. The objectives of this preliminary assessment were to identify and roughly quantify the potential benefits and penalties of launching the Mid-L/D without a PLF, including the integrated performance impacts.

In general, there are several potential benefits associated with launching an aerodynamic vehicle without a payload fairing. First, the elimination of a unique SLS PLF configuration also eliminates the time and resources needed to develop, certify, and maintain that PLF configuration. Second, the diameter constraints on the spacecraft are relaxed since the inner dynamic envelope of the PLF is no longer a factor. Analysis showed that photographically scaling the Mid-L/D concept to fit within the SLS $8.4 \mathrm{~m}$ fairing would reduce usable internal dimensions and internal volume by nearly $18 \%$ and $44 \%$, respectively. Even the deployable vehicle concepts (HIAD and ADEPT) using vertically stacked payload configurations lose roughly $32 \%$ of their deck area when scaled down from $9.1 \mathrm{~m}$ to $7.5 \mathrm{~m}$ diameter, forcing the Mars payloads to increase in height. Third, launching without a payload fairing enables spacecraft designers to avoid folding wings or other complex deployable elements involving dynamic seals and mechanisms. Finally, the 
absence of a PLF simplifies the ascent abort process for crewed vehicles (although this is not a consideration for the current Mars architecture because the crew is launched separately from the landers).

Likewise, there are penalties for launching the Mid-L/D vehicle without a payload fairing. First, there is the cost associated with the development, certification, and maintenance of an additional, unique ascent aerodynamic database. Second, there is the cost associated with the development, certification, and maintenance of a new set of SLS loads with potential impacts to the SLS upper stage. Third, there is a potential need to modify SLS operational rules and constraints such as day of launch placards on ground winds and winds aloft, engine throttle profile, trajectory shaping, max q, q-alpha limit, wind gust loading and flight performance reserves. Furthermore, a unique payload attachment fitting and aerodynamic fairing may be required to blend from the Mid-L/D shape to the SLS upper stage. Please note that the mass impact of adding an aerodynamic skirt around the base of the CobraMRV was not assessed for this assessment. The spacecraft mass will increase from the addition of PLF-specific features which must be carried throughout the mission, including lightning protection, additional acoustic material, purge systems, umbilical connections, and access doors. Finally, there is an increased risk of damage to critical spacecraft TPS from exposure to wildlife and inclement weather during rollout, pad operations, and launch.

Data obtained from the design documentation for the $8.4 \mathrm{~m}$ diameter $\mathrm{x} 19.1 \mathrm{~m}$ tall SLS PLF is shown in Table 5. A mass growth allowance of $18 \%$ is applied to each component per the SLS PLF documentation. In addition, a $10 \%$ penalty to the primary structure was estimated by comparing the reference $5 \mathrm{~g}$ axial acceleration load case to a maximum dynamic pressure load case (assumed $38.3 \mathrm{kPa}$ or $800 \mathrm{psf}$ ) combined with a $2 \mathrm{~g}$ axial acceleration. The mass comparison was made with the CobraMRV configuration without cargo bay doors from Table 1. The total estimated mass impact of using the CobraMRV as the SLS launch fairing is provided in Table 6. Categories 1.3 and 6.5 were added to the MEL to approximate the mass impacts of eliminating the SLS PLF. First-order estimate for the increase in the CobraMRV mass for PLF-specific systems and components is approximately 3.3t. This additional mass is be carried from Earth launch through Mars landing, impacting both the in-space transportation element and the postseparation lander maneuvers at Mars from aerocapture through EDL.

PLFs are typically jettisoned as early as possible during ascent (usually around a dynamic pressure of $24 \mathrm{~Pa}$ or 0.5 psf) to maximize the launch vehicle injected mass performance. The injected mass benefit of PLF jettison varies depending on the launch vehicle design, ascent trajectory, and injection target, but a commonly used rule of thumb is a ratio of 8:1 (ratio of PLF mass to injected mass increase) based on the PLF separable mass. For example, the elimination of an SLS 8.4m PLF with a mass of $6272 \mathrm{~kg}$ (6124 kg separable) results in an estimated injected mass benefit of roughly $766 \mathrm{~kg}$. The mass impact of adding an aerodynamic skirt around the base of the CobraMRV was not assessed for this study. While the use of a Mid L/D vehicle as the launch vehicle fairing may reduce the total launch mass and allow it to be delivered to a higher Earth orbit, it increases the total mass of the system that travels to Mars. Thus, the overall mass efficiency of the Mars mission architecture may be adversely impacted by launching the lander without a PLF.

Table 5. SLS payload fairing subsystem masses.

\begin{tabular}{|c|c|c|c|c|c|c|}
\hline ID & Subsystem & Unit (kg) & Basic (kg) & MGA (\%) & MGA (kg) & Predicted (kg) \\
\hline 6.5 & SLS PLF-Specific Components & & 1094 & $18 \%$ & 197 & 1292 \\
\hline 6.5 .1 & Lightning Protection System & 85.3 & 85.3 & $18 \%$ & 15.4 & 100.7 \\
\hline 6.5 .2 & Acoustic Material & 705.8 & 705.8 & $18 \%$ & 127.0 & 832.8 \\
\hline 6.5 .3 & Purge System & 255.3 & 255.3 & $18 \%$ & 46.0 & 301.3 \\
\hline 6.5 .4 & Umbilical & 65.8 & 65.8 & $18 \%$ & 11.8 & 77.6 \\
\hline 6.5 .5 & Access Doors & 67.6 & 67.6 & $18 \%$ & 12.2 & 79.8 \\
\hline
\end{tabular}

Table 6. CobraMRV MEL containing elements required if using the vehicle as the launch shroud.

\begin{tabular}{|l|l|r|r|}
\hline \multicolumn{1}{|c|}{ ID } & Subsystem & $\begin{array}{c}\text { No CBDs No SLS PLF } \\
\text { Predicted Mass (kg) }\end{array}$ & $\begin{array}{l}\text { No CBD with SLS PLF } \\
\text { Predicted Mass (kg) }\end{array}$ \\
\hline $\mathbf{1 . 0}$ & Structures & $\mathbf{1 6 , 0 6 6}$ & $\mathbf{1 4 , 7 8 2}$ \\
\hline 1.1 & Primary Structure & 12,838 & 12,838 \\
\hline 1.2 & Secondary Structure & 1,944 & 1,944 \\
\hline 1.3 & Structural Adjustment for Eliminating the PLF & 1,284 & 0 \\
\hline $\mathbf{2 . 0}$ & Propulsion & $\mathbf{5 , 2 6 3}$ & $\mathbf{5 , 2 6 3}$ \\
\hline $\mathbf{3 . 0}$ & Power & $\mathbf{1 , 2 1 7}$ & $\mathbf{1 , 2 1 7}$ \\
\hline
\end{tabular}




\begin{tabular}{|c|c|c|c|}
\hline 4.0 & Avionics & 333 & 333 \\
\hline 5.0 & Thermal & 844 & 844 \\
\hline 6.0 & Aero decelerator & 6,790 & 5,499 \\
\hline 6.1 & $T P S$ & 3,032 & 3,032 \\
\hline 6.2 & Aerosurfaces & 520 & 520 \\
\hline 6.3 & Mechanisms & 962 & 962 \\
\hline 6.4 & Landing Gear & 985 & 985 \\
\hline 6.5 & SLS PLF-Specific Components & 1,292 & 0 \\
\hline \multicolumn{2}{|c|}{ Dry Mass } & 30,513 & 27,938 \\
\hline 7.0 & Cargo & 20,000 & 20,000 \\
\hline 8.0 & Non-Propelled Fluids & 966 & 966 \\
\hline \multicolumn{2}{|c|}{ Inert Mass } & 51,479 & 48,904 \\
\hline 9.0 & Used Propellant & 15,797 & 15,018 \\
\hline 9.1 & Usable Propellant (MPS) & 10,407 & 9,886 \\
\hline 9.2 & Usable Propellant (RCS) & 5,163 & 4,905 \\
\hline 9.3 & Engine Start/Stop Transients (MPS) & 227 & 227 \\
\hline \multicolumn{2}{|c|}{ Total Stage Gross Launch Mass } & 67,276 & 63,922 \\
\hline
\end{tabular}

\section{Findings and Recommendations}

This section summarizes key findings from the EDLAS Phase 2 rigid vehicle analysis. First, it has been verified that a rigid body concept can be designed to meet the human Mars EDL constraints and objectives, assuming the SLS payload fairing diameter of $10 \mathrm{~m}$ is utilized. Second, reducing the SLS shroud diameter from $10 \mathrm{~m}$ to $8.4 \mathrm{~m}$ diameter has significant impacts on the EDL vehicle design and the Mars architecture. These include reduced payload volume, reduced packaging flexibility and margin, increased number of launches and landings over the $10 \mathrm{~m}$ diameter fairing delivering the same payload manifest, and elimination of the ability to accommodate even the small (Low Mars Orbit) MAV in the capsule. Ultimately, the increase number of landers lengthens the delivery schedule and increases over all mission cost and risk. Therefore, the $10 \mathrm{~m}$ diameter SLS fairing is critical to achieving the Mars architecture as defined by HEOMD. Third, the capsule concept, described herein, cannot accommodate the surface mission payload manifest in four landers. Significant architecture modifications must be made to make the capsule an acceptable option. Architecture modifications include a smaller MAV, taxi vehicle, more launches, larger landing zone, and longer mission timeline compared to the other entry configurations being considered. The vehicle is launched as the SLS shroud, which initial analysis indicates will further increase its system mass. Fourth, simulation results indicate that the rigid mid-L/D vehicle (CobraMRV) is controllable with Shuttle-size center of gravity limitations using flaps and RCS jets through aerocapture and entry given sufficient aerodynamic definition. However, additional thrust may be advantageous to maintain vehicle thrust-to-weight for enhancing the landing targeting capability and reducing propellant usage.

These primary findings influence the technology investment recommendations for the rigid vehicles. Because of the complications and architecture modifications required to make the capsule design close, the recommendation is to focus future resources on one rigid vehicle, the Mid L/D concept. However, many aspects of the Mid L/D vehicle design need to be further analyzed and understood, including the vehicle controllability and stability when engines are initiated in a supersonic flow environment, navigation sensor requirements to meet landing accuracy, refining designs for mass reductions and payload offloading and refining payload definitions for horizontal rather than vertical packaging arrangements. Future study efforts and technology investments should address these design aspects.

\section{Conclusion}

This paper describes the analysis and trades performed in EDLAS Phase 2 for the rigid vehicle concepts, the mid L/D CobraMRV and low L/D capsule. Analysis to develop and refine mass model estimates for each concept using similar subsystem masses and margins is presented. The rigid vehicles are the most massive of the EDLAS configurations, however, they offer superior payload protection from entry and landing environments and orbital debris, and utilize historically flight-proven construction and testing techniques. The packaging assessment showed that some modification was needed to accommodate key payload elements like the habitat. The ample volume available in the CobraMRV allowed for a reconfiguration of the monolithic habitat, while the capsule required a 
modular habitat and an extra lander to deliver it. The full-size MAV did not adequately fit in the capsule configuration, resulting in a smaller MAV and the addition of an architecture element, the taxi. Likewise, the volume constrained capsule could not accommodate all the payload in Lander 3, necessitating yet another vehicle. The need for additional launch vehicles, and the subsequent impact on cost and schedule are the primary reasons that continued work on the capsule configuration is not recommended in future human Mars studies using the current long stay architecture. However, this does not imply that the capsule is not a capable technology for landing larger payload mass. Nonetheless, it does not satisfy the ground rules and assumption set forth by this study.

The CobraMRV, while leveraging shuttle heritage, is not a shape that has flown at Mars. However, the configuration offers many advantages for human missions to Mars such as reduced technology development, proven construction and testing techniques, packaging flexibility, scalability, surface operations flexibility, the option to fly as the SLS fairing and it protects the payload in all phases of flight. For these reasons, the CobraMRV configuration is recommended for future human Mars mission studies. Future work includes characterizing the engine plume interaction with the vehicle and developing an end-to-end six degree-of-freedom simulation that models entry and descent guidance and control, engine transients, navigation sensor performance and flow transition effects over the body, Additional work to optimize the vehicle length and payload packaging, and to continue to refine the mass estimate is also suggested. Finally, note that risk and development costs were not specifically analyzed in detail in this study and should be addressed.

In conclusion, EDLAS continues to refine the understanding of the complex and interconnected nature of the challenge to put humans on Mars. Every assumption has significant implications that impact vehicle designs from preEarth launch to Mars ascent and thus EDL design decisions must be made in the context of the larger architecture. Recommended work on the Mid L/D configuration will continue through the upcoming year.

\section{Acknowledgments}

The authors would like to acknowledge the Science Technology Mission Directorate (STMD) and the Human Exploration and Operations Mission Directorate (HEOMD) for their continued support of this and other studies that continue to challenge our EDL paradigms. The authors would like to recognize specific individuals who made significant contributions to the work presented herein including Hilmi Alkamhawi, Mike Baysinger, Ellen Braden, Stan Bouslog, Jeff Bowles, Breanna Johnson, D.R. Komar, David Kinney, Chris Lang, Ben Nikaido, Dan Matz, Richard Powell, Susan Stachowiak, Paul Tartabini, H. Dan Thomas and all the members of the EDLAS Team. They come from many NASA centers including, Ames Research Center, Langley Research Center, Johnson Spaceflight

Center and Marshal Space Flight Center, as well as, external contractors and those in academia.

\section{References}

[1] Cianciolo, A. D. and Polsgrove, T. T., "Human Mars Entry, Descent and Landing Architecture Study: Phase 2 Summary," AIAA SPACE 2018 Abstract Submitted. Sept. 2018.

[2] Jefferies, S., Collins, T., Cianciolo, A. D., Polsgrove T. "Impacts of Launch Vehicle Faring Size on Human Exploration Architectures" 2017 IEEE Aerospace Conference, 4-11 March 2017 10.1109/AERO.2017.7943833

[3] Cerimele, C. J., Robertson, E. A., Sostaric, R. R. (editor), Campbell, C. H., Robinson, P., Matz, D. A., Johnson, B. J., Stachowiak, S. J., Garcia, J. A., Bowles, J. V., Kinney, D. J., Theisinger, J. E. "A Rigid Mid-Lift-to-Drag Ratio Approach to Human Mars Entry, Descent, and Landing” AIAA Paper 2017-1898, Feb 2017.

[4] Drake, B. (editor), "Human Exploration of Mars Design Reference Architecture 5.0," NASA/SP-2009-566.

[5] Dwyer Cianciolo, A.M., et al., "Entry, Descent and Landing Systems Analysis Study: Phase 1 Report," NASA-TM-2010216720, July 2010.

[6] Price, H., Manning, R., Sklyanskiy, E., Braun, R., "A High-Heritage Blunt-Body Entry, Descent, and Landing Concept for Human Mars Exploration," AIAA-2016-0219.

[7] Arthur, George R, "Lunar Spacecraft Designs", Advanced in the Astronautical Sciences, Vol. 10, 1963, p. 52.

[8] Cianciolo, A. D., Dillman, R., Brune, A., Lugo, R., Polsgrove, T. T., Percy, T. K., Sutherlin, S and Cassell, A., "Human Mars Entry, Descent and Landing Architecture Study: Deployable Decelerators," AIAA SPACE 2018 Abstract Submitted. Sept. 2018.

[9] Walker, S. P., Daryabeigi, K., Samareh, J., Wagner, R., and Waters, A., "A Multifunctional Hot Structure Heatshield Concept for Planetary Entry," 20th AIAA International Space Planes and Hypersonic Systems and Technologies Conference (Hypersonics 2015); 6-9 Jul. 2015; Glasgow, Scotland; United Kingdom.

[10]Justus, C. G., Johnson, D. L., "Mars Global Reference Atmospheric Model 2001 Version (Mars-GRAM 2001): Users Guide" NASA/TM-2001-210961.

[11] Horvath, T. J., O’Connell, T. F., Cheatwood, F. M., Prabhu, R. K., Alter, S. J., "Experimental Hypersonic Aerodynamic Characteristics of Mars Surveyor 2001 Precision Lander with Flap," Journal of Spacecraft and Rockets, Vol. 43, No. 2, MarchApril 2006, pp. 270-281. 
[12] Johnson, B. J., Braden, E. M., Sostaric, R. R., Cerimele, C. J., Lu, P. "Entry, Descent, and Landing Performance for a MidLift-to-Drag Ratio Vehicle at Mars" AAS Feb. 2018.

[13] Johnson, B. J., Cerimele, C. J., Stachowiak, S. J., Sostaric, R. R., Matz, D., Lu, P. "Mid-Lift-to-Drag Ratio Vehicle Control System Design and Simulation for Human Mars Entry" AIAA Paper 2018-0615, Jan. 2018.

[14] Rucker, M. A., Oleson, S., George, P., Landis, G. A., Fincannon, J., Bogner, A., Jones, R. E., Turnbull, E., McNatt, J., Marini, M. C., Gyekenyesi, J. Z., Colozza, A. J., Schmitz, P. C., Packard, T. W. "Solar Versus Fission Surface Power for Mars" AIAA Paper 2016-5452, Sept. 2016. 